\title{
Caspase-2 is not required for thymocyte or neuronal apoptosis even though cleavage of caspase-2 is dependent on both Apaf-1 and caspase-9
}

\author{
LA O'Reilly ${ }^{\star, 1}$, P Ekert ${ }^{1,3}$, N Harvey ${ }^{2}$, V Marsden ${ }^{1}$, L Cullen ${ }^{1}$, \\ DL Vaux ${ }^{1}$, Hacker $^{1,6}, C_{\text {Magnusson }}{ }^{1,7}$, M Pakusch $^{1}$, \\ F Cecconi ${ }^{4}$, K Kuida ${ }^{5}$, A Strasser ${ }^{1}$, DCS Huang ${ }^{1}$ and \\ S Kumar, ${ }^{\star 2}$ \\ 1 The Walter and Eliza Hall Institute of Medical Research, Melbourne, Australia \\ 2 The Hanson Centre for Cancer Research, Institute of Medical and Veterinary \\ Science, Adelaide, Australia \\ 3 Murdoch Children's Research Institute, Melbourne, Australia \\ ${ }^{4}$ University of Rome 'Tor vergata', Rome, Italy. \\ ${ }^{5}$ Vertex Pharmaceuticals, Cambridge, MA, USA. \\ ${ }^{6}$ Current address: Technical University of Munich, Munich, Germany \\ 7 Current address: Pharmacia, Uppsala, Sweden \\ * Corresponding authors: LA O'Reilly, The Walter and Eliza Hall Institute of \\ Medical Research, Post Office, Royal Melbourne Hospital, Victoria 3050, \\ Australia. Tel: +61-3-9345 2555; Fax: +61-3-9347-0852; \\ E-mail: oreilly@wehi.edu.au; or \\ S Kumar, Molecular Regulation Laboratory, Hanson Centre for Cancer \\ Research, Institute of Medical and Veterinary Science, P0 Box 14, Rundle Mall, \\ Adelaide 5000, Australia. Tel: +61-8-8222 3738; Fax: +61-8-8222-3139; \\ E-mail: sharad.kumar@imvs.sa.gov.au
}

Received 29.11.01; revised 28.1.02; accepted 8.2.02 Edited by SJ Martin

\begin{abstract}
We have generated rat monoclonal antibodies that specifically recognise caspase-2 from many species, including mouse, rat and humans. Using these antibodies, we have investigated caspase-2 expression, subcellular localisation and processing. We demonstrate that caspase-2 is expressed in most tissues and cell types. Cell fractionation and immunohistochemistry experiments show that caspase- 2 is found in the nuclear and cytosolic fractions, including a significant portion present in the Golgi complex. We found that caspase-2 is processed in response to many apoptotic stimuli but experiments with caspase-2 deficient mice demonstrated that it is not required for apoptosis of thymocytes or dorsal root ganglia (DRG) neurons in response to a variety of cytotoxic stimuli. Caspase-2 processing does not occur in thymocytes lacking Apaf-1 or caspase-9, suggesting that in this cell type, activation of caspase-2 occurs downstream of apoptosome formation.

Cell Death and Differentiation (2002) 9, 832-841. doi:10.1038/ sj.cdd. 4401033
\end{abstract}

Keywords: caspase-2; monoclonal antibody; apoptosis; subcelIular localisation; caspase-9; Apaf-1
Abbreviations: LM, light membrane; HM, heavy membrane; $m A b$, monoclonal antibody; NGF, Nerve Growth Factor; ECL, enhanced chemical luminescence; zVAD-fmk, benzyloxy-carbonyl-Val-AlaAsp-fluoromethylketone; DEX, dexamethasone; DRG, dorsal root ganglion

\section{Introduction}

The Caenorhabditis elegans cysteine protease, CED-3, and its mammalian homologues, constitute the effector arm of the apoptotic machinery. These enzymes are produced as zymogens which undergo processing into two subunits of $\sim 20$ and $\sim 10 \mathrm{kDa}$ that are assembled into the active enzyme (reviewed in references ${ }^{1,2}$ ). Mammalian cells have at least two distinct caspase activation pathways. ${ }^{3}$ Death receptors of the tumour necrosis factor receptor (TNFR) family recruit FADD, an adaptor molecule which in turn recruits pro-caspase-8 or -10 to the death inducing signalling complex (DISC). ${ }^{4,5}$ The recruitment of pro-caspase-8 or -10 to the DISC promotes caspase-8/-10 processing ${ }^{6,7}$ by a mechanism that is thought to involve proximity-induced autoactivation of the pro-caspases. ${ }^{8}$ The second apoptosis signalling pathway is regulated by the Bcl-2 family of proteins and is initiated by a different set of initiator caspases and their adaptors. Mammalian caspase-9 contains an $\mathrm{N}$-terminal caspase recruitment domain (CARD), which mediates interaction with its adaptor Apaf- $1 .{ }^{9}$ Once activated, Apaf- 1 recruits pro-caspase- 9 to form the apoptosome protein complex. In a manner analogous to procaspase-8 activation, recruitment of pro-caspase- 9 via its adaptor serves to bring pro-caspase molecules into close proximity, precipitating their activation. ${ }^{9,10}$

Structurally, mammalian caspase-2 closely resembles caspase-9 and CED-3 ${ }^{11,12}$ and previous studies have implicated caspase-2 in a variety of cell death pathways. ${ }^{11,13}$ The question, however remains, at what stage in the apoptotic process does caspase-2 act, since it has features of both upstream caspases (CARD pro-domain) and effector caspases (DEXD substrate specificity). ${ }^{14}$ Caspase-2 CARD has been shown to interact with the CARD present in the adaptor protein RAIDD, ${ }^{15}$ which when overexpressed in mammalian cells induces apoptosis. It remains, however, unclear whether RAIDD is necessary for caspase-2 activation ${ }^{16}$ and whether it plays a role in the apoptotic process. In many cell types, caspase-2 is processed early during apoptosis. ${ }^{17}$ Furthermore, overexpressed procaspase-2 can homodimerise in a CARD dependent manner and autoprocess. ${ }^{18,19}$ However, other studies have indicated that caspase-2 functions further downstream as an effector caspase. For example, caspase-3 can efficiently process pro-caspase- $2,{ }^{20}$ indicating that caspase-2 activation may occur downstream of this effector 
caspase. One possible scenario is that initial activation of caspase- 2 occurs by an autocatalytic mechanism, but once effector caspases, such as caspase-3, have been activated, they are responsible for the bulk of pro-caspase-2 processing, forming an amplification loop.

In order to address the issue of whether caspase-2 is an initiator or effector caspase, we generated highly specific monoclonal antibodies against this protease. Using thymocytes derived from Apaf-1 $1^{-1-}$ and caspase $-9^{-1-}$-deficient mice, we demonstrate that at least in this cell type, caspase- 9 and Apaf- 1 are required for caspase- 2 processing indicating that cleavage of caspase-2 lies downstream of the Apaf-1/ caspase- 9 apoptosome. Furthermore, we have generated caspase-2-deficient mice and show that caspase-2 is dispensible for apoptosis of thymocytes or DRG neuronal cells induced by cytokine withdrawal or several stress stimuli.

These antibodies allowed us to confirm and extend the expression pattern of caspase-2 in mouse tissues ${ }^{21}$ and an extensive array of cell lines and to determine its subcellular localisation by subcellular fractionation. We show that caspase-2 is expressed in most tissues and cell types and that a significant proportion of caspase-2 is in the nucleus and within the Golgi apparatus.

\section{Results and discussion}

\section{Characterisation of monoclonal antibodies to Caspase-2}

Monoclonal antibodies recognising native mouse caspase-2 were identified by immunofluorescence staining and flow cytometric analysis using a previously described protocol. $^{22}$ 293T cells transfected with a plasmid encoding a C-terminally hemagglutinin (HA)-tagged caspase-2 in which the active site cysteine was replaced by alanine were stained with hybridoma supernatants plus FITC-conjugated goat anti-rat IgG antibodies and analyzed in a FACScan. Antibodies specific to caspase-2 were revealed by a double immunofluorescence peak (Figure 1D-F) similar to the profile obtained by staining with the anti-HA epitope tag-specific antibody (Figure 1A). The peak with lower intensity represents background immunofluorescence of untransfected 293T cells and the higher intensity peak represents specific caspase-2 staining in the transfected HA-caspase-2 expressing 293T cells. From an initial screen of 2000 hybridoma cultures, 17 anti-caspase-2 antibody-secreting hybridomas were selected, expanded and subcloned.

Two independent mAbs, $10 \mathrm{C} 6$ and 11B4, that recognise mouse, human, rat and monkey caspase-2 in immunofluorescence staining, Western blotting and immunoprecipitation (Figure 1G-I), were chosen for further experiments. In tissues from normal mice both mAbs detected by Western blotting a single protein of $\sim 51 \mathrm{kDa}$, corresponding to endogenous full length pro-caspase-2 (Figure 1G). The 10C6 and 11B4 (Figure 1G) antibodies were highly specific for caspase-2 since no crossreactivity to other proteins was observed by Western blotting and no protein band was detected in tissues made from caspase$2^{-1-}$ mice (Figures $1 \mathrm{G}, 2$ ). These results document that the monoclonal antibodies 10C6 and 11B4 are suitable reagents to investigate caspase-2 expression, localisation and processing.

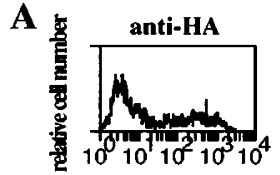

$\mathbf{B}_{\mathbf{c}}$

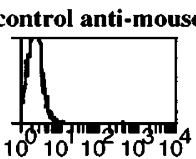

D

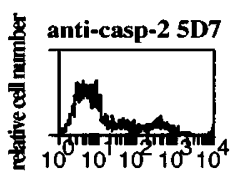

$\mathbf{E}$

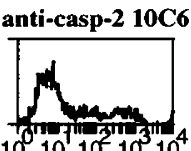

I

\begin{tabular}{cc}
$\begin{array}{c}\text { Antibody } \\
\text { Clone }\end{array}$ & Isoty \\
\hline 5D 7 & IgG 1 \\
$10 \mathrm{C} 6$ & IgG2 \\
$11 \mathrm{~B} 4$ & IgG2
\end{tabular}

C

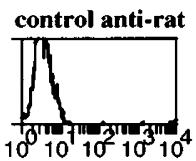

$\mathbf{F}$
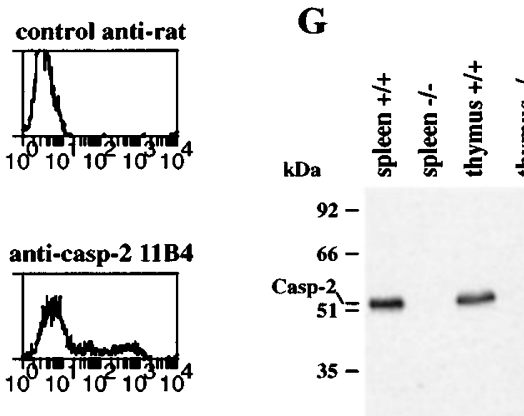

$25-$ Hsp-70

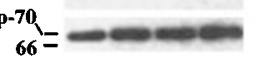

hs mm ca rn

$\mathrm{WB} / \mathrm{IP} / \mathrm{FF}$

WB/IP/IF/ELISA/IH

hs $\mathrm{mm}$ ca rn

hs $\mathrm{mm}$ ca rn

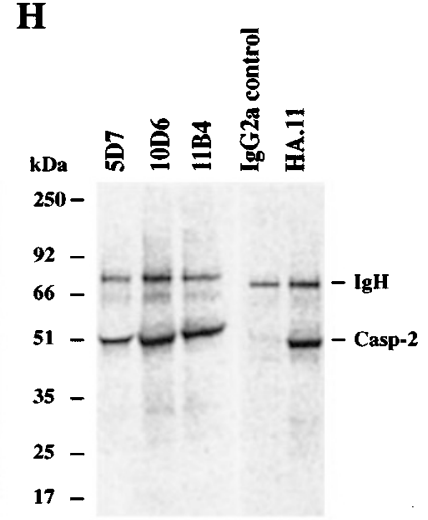

Figure 1 Screening for caspase-2 specific monoclonal antibodies (mAbs). 293T cells were transiently transfected with a construct encoding a haemaglutinin (HA) epitope tagged caspase-2 mutant in which the active site cysteine had been replaced by alanine. Transfected cells were fixed, permeabilised and stained with mouse anti-HA mAb (A, positive control), with secondary antibody alone (B and C, negative controls), or the rat anti-caspase-2 mAbs 5D7 (D), 10C6 (E) or 11B4 (F). Staining was visualised by FITC-conjugated goat anti-mouse IgG antibodies (A, B) or FITC-conjugated goat anti-rat IgG antibodies (C-F). (G) Western blotting with anti-caspase-2 mAb 11B4 revealed caspase-2 protein in lysates from wild type (wt) spleens and thymi but not in tissues from caspase-2 ${ }^{-1-}$ mice (upper panel) (similar results were obtained with anti-caspase-2 clone 10C6) and probing with an anti-Hsp70 mAb was used as loading control (lower panel). (H) Immunoprecipitation with anti-caspase-2 mAbs 5D7, 10C6, 11B4, an isotype-matched control antibody or the anti-HA mAb of ${ }^{35} \mathrm{~S}-$ labelled $293 \mathrm{~T}$ cells transfected with mutant caspase-2 HA. (I) Summary of the characteristics of the anti-caspase-2 mAbs 5D7, 10C6 and 11B4. All antibodies recognise human (hs), mouse (mm), monkey (ca) and rat ( $\mathrm{rn}$ ) caspase-2 protein by immunofluorescence staining (IF), immunopecipitation (IP), immunohistochemistry (IH), enzyme linked immunoadsorbant assay (ELISA) and Western blotting (WB) 


\section{Caspase-2 activation during apoptosis}

In cells undergoing apoptosis, both anti-caspase-2 mAbs detected not only the $51 \mathrm{kDa}$ zymogen, but also of the products of caspase- 2 processing, namely the $32 / 33 \mathrm{kDa}$ doublet, and the $19 \mathrm{kDa}$ subunit. These cleavage products were observed in BAF-3, FDC-P1 and HeLa cells upon apoptosis induction by a variety of stress conditions, such as IL-3 deprivation (Figure 3 and data not shown) or treatment with staurosporine or UV-irradiation (not shown). In all cases, processing of caspase-2 was rapid. For example, caspase-2 cleavage products became visible within $4 \mathrm{~h}$ of IL-3 withdrawal from BAF-3 cells. Interestingly, treatment of IL-3 deprived BAF-3 cells with the broad spectrum caspase inhibitor zVAD-fmk prevented the generation of $\mathrm{p} 19$ subunits, but had no impact on the appearance of the $32 / 33 \mathrm{kDa}$ polypeptides, which probably represent prodomain-less caspase-2. As caspase-2 is insensitive to zVAD-fmk, ${ }^{23}$ this observation may indicate that the intermediate product in these cells is generated by autocatalytic activation of caspase-2, whereas, generation of the mature subunit, p19, may require a zVAD-fmk sensitive caspase, such as caspase3. Alternatively, the first cleavage step may be mediated by an initiator caspase that is insensitive to ZVAD-fmk or not easily accessible to zVAD-fmk perhaps due to sequestration inside an organelle.

\section{Expression of caspase-2 in cell lines and mouse tissues}

Caspase-2 expression in cell lines was determined by Western blotting. Examples of such Western blots are shown in Figure $4 \mathrm{~A}$ and the overall results are summarised in Table 1. Readily detectable levels of caspase-2 were found in cell lines of lymphoid ( $B$ and T), myeloid, erythroid, fibroblast and epithelial origin. A broad survey of normal adult mouse tissues by Western blotting readily detected caspase-2 in the brain (E15), thymus, spleen, lymph nodes, colon, small intestine and testes (Figure 4B). Low levels of caspase-2 were found in the kidney, salivary gland and heart, but little or no caspase-2 expression could be detected in pancreas or liver (Figure 4B). This contrasts with the ubiquitous expression of caspase-2 mRNA observed during embryogenesis. ${ }^{11}$ This may indicate that caspase-2 expression differs between embryo and adult tissues. These results confirm previous observations on the tissue expression of caspase- $2^{21}$ and extend them by demonstrating that caspase-2 is also expressed at high levels in the testes and colon, is barely detectable in the salivary gland and absent from pancreas. Overall these results indicate a possible role for caspase-2 during development and in hematopoetic cells in the adult.

The smaller $\sim 35 \mathrm{kDa}$ band $\left(^{*}\right)$ observed in Western blots in some tissues, such as the lung, kidney, spleen (E15) and brain (E15) is most likely a processing intermediate (see above). It is, however, also possible that

Table 1 Summary of Western blot analysis of caspase-2 protein expression in cell lines

\begin{tabular}{|c|c|c|c|}
\hline Cell line & Origin & Species & $\begin{array}{c}\text { caspase- } \\
2\end{array}$ \\
\hline ABLS 8.1 & pre-B lymphoma & mouse & + \\
\hline $70 X / 3$ & B lymphoma & mouse & + \\
\hline $\mathrm{CH} 1$ & B lymphoma & mouse & + \\
\hline Sp2/0 & plasmacytoma & mouse & + \\
\hline NS-1 & plasmacytoma & mouse & + \\
\hline K052 DA.20 & T lymphoma & mouse & + \\
\hline WEHI 7.1 & T lymphoma & mouse & + \\
\hline WEHI 703* & T lymphoma & mouse & + \\
\hline EL-4.1 & T lymphoma & mouse & + \\
\hline B6.2.16.BW2\# & T lymphoma & mouse & + \\
\hline Jurkat & T lymphoma & human & + \\
\hline P388D1 & Macrophage & mouse & + \\
\hline RAW 2645.7 & Macrophage & mouse & + \\
\hline J774 & Macrophage & mouse & + \\
\hline F4N & erythroleukaemia & mouse & + \\
\hline TS5 & erythroleukaemia & mouse & + \\
\hline CP16 & erythroleukaemia & mouse & + \\
\hline 34.6Myl & granulocyte & mouse & + \\
\hline$P-815 X-2.1$ & mastocytoma & mouse & + \\
\hline 416B MEG & megakaryocyte & mouse & + \\
\hline 416B & myeloid & mouse & + \\
\hline FDC-1 & myeloid & mouse & + \\
\hline BAF-3 & myeloid & mouse & + \\
\hline $\mathrm{NIH} / 3 \mathrm{~T} 3$ & fibroblast & mouse & + \\
\hline Rat1 & fibroblast & rat & + \\
\hline L-929 & fibroblast & mouse & + \\
\hline WEHI 11 & fibrosarcoma & mouse & + \\
\hline WEHI 164 & fibrosarcoma & mouse & + \\
\hline S17 & stromal & mouse & + \\
\hline MDCK & kidney & dog & + \\
\hline MCF-7 & breast carcinoma (epithelial) & human & + \\
\hline HK-2 & kidney & human & + \\
\hline 293T & embryonic kidney & human & + \\
\hline G-401 & Wilm's tumour (kidney) & human & + \\
\hline TCMK-1 & kidney & mouse & + \\
\hline Cosm6 & kidney (fibroblast) & monkey & + \\
\hline MH134 & hepatoma & mouse & + \\
\hline HepG2 & liver (epithelial) & human & + \\
\hline SW480 & colon carcinoma & human & + \\
\hline EB-3 & colon carcinoma & human & + \\
\hline HeLa & cervical carcinoma & human & + \\
\hline caspase 2-/- & thymus & mouse & - \\
\hline caspase-2/-/- & spleen & mouse & - \\
\hline caspase-2-/- & brain & mouse & - \\
\hline
\end{tabular}

${ }^{*}$ Activated $\mathrm{N}$-Ras transgenic mouse thymic $\mathrm{T}$ cell lymphoma. \#Mouse $\mathrm{T}$ hybridoma expressing the same receptor as anti-HY TCR transgenic cells. $\sim$ Megakaryocyte differentiation induced by GATA-1 expression

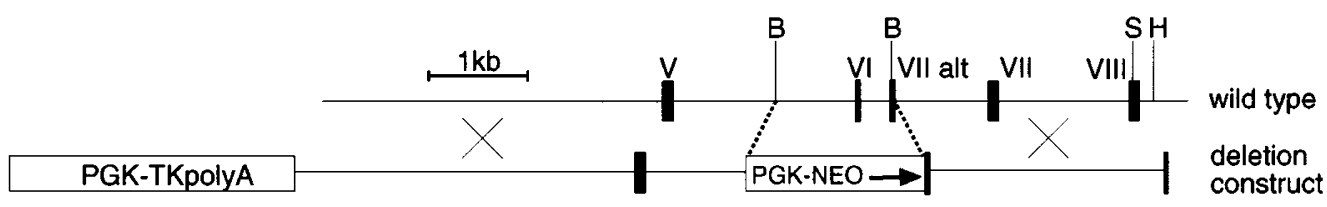

Figure 2 Targeted disruption of the mouse caspase-2 gene. Roman numerals denote exons. BamHI, Sall and Hindll sites are denoted 'B', 'S' and ' $\mathrm{H}$ ', respectively. Exon VI which encodes for residues including the catalytic cysteine residue of caspase -2 and exon VII were all replaced by the PGK-NEO cassette 


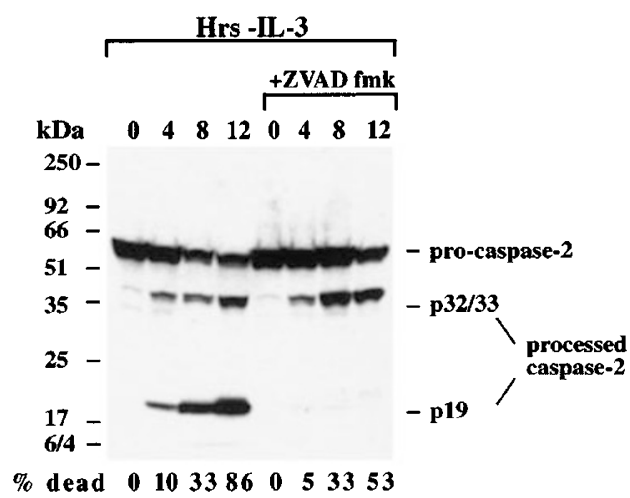

Figure 3 Caspase-2 mAbs detect the products of caspase-2 processing during apoptosis induction. Cell death was induced in BAF-3 cells by withdrawal of IL-3 and cell lysates were prepared $0,4,8$ and $12 \mathrm{~h}$ after apoptosis induction. Caspase-2 expression and processing was assessed by Western blotting using anti-caspase-2 mAb 11B4 and detected by ECL. Figures below the blot indicate the percentage of dead cells as assessed by trypan blue exclusion
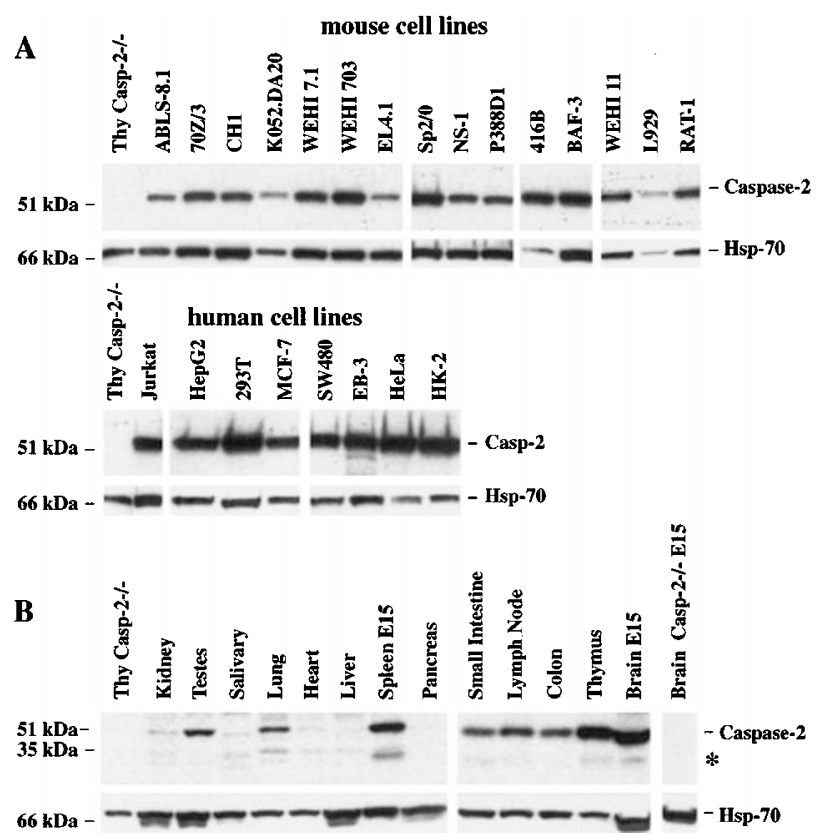

Figure 4 (A) Caspase-2 expression in cultured mouse and human cell lines. Caspase-2 protein was revealed in lysates from $2 \times 10^{5}$ mouse and human cell lines by Western blotting with anti-caspase-2 mAb 11B4 and detection by ECL. (B) Expression of caspase-2 by Western blot analysis in tissue lysates from normal and caspase- $2^{-1-}$ mice $(250 \mu \mathrm{g}$ total protein/lane). Probing with an anti-Hsp70 mAb was used as loading control for all blots. ( $\left.{ }^{*}\right)$ may represent caspase-2 (short) or processed caspase-2

this $\sim 35 \mathrm{kDa}$ band could be the putative short form of caspase-2 (Nedd2s/lch-1s, $343 \alpha \alpha$ ), which has been reported to be expressed at the mRNA level in similar tissues, such as the brain, skeletal muscle and to a lesser extent the spleen, lung, gut, testis and kidney. ${ }^{24}$ The function of Nedd2s/lch-1s remains poorly defined, although it has been suggested to inhibit apoptosis in certain neuronal populations. ${ }^{21,25}$

\section{Subcellular localisation of caspase-2}

The subcellular localisation of pro-caspase-2 remains controversial. Some of us have previously shown that GFPtagged pro-caspase-2 localises to the cytoplasm and the nucleus and can be processed in both compartments. ${ }^{19}$ Subsequent studies using subcellular fractionation and a polyclonal anti-caspase- 2 antibody ${ }^{26}$ showed that pro-caspase-2 was located in the cytosol, nucleus and mitochondria. $^{27}$ Recent studies by Mancini ${ }^{28}$ demonstrated that caspase-2 is predominantly located in the Golgi complex and nucleus.

To determine the localisation of pro-caspase-2, we performed sub-cellular fractionation and confocal microscopy analyses on cells expressing endogenous caspase-2. We chose to mechanically disrupt cells by Dounce homogenisation, rather than lysing them with non-ionic detergents, because these reagents have been shown to cause artefactual changes in localisation of some cell death regulators. ${ }^{29}$ Subcellular fractions of healthy Jurkat cells were analyzed by immunoblotting with mAbs $10 \mathrm{C} 6$ and 11B4 (Figure 5A). Endogenous pro-caspase-2 protein was predominantly associated with the cytosolic fraction, the latter includes most of the Golgi apparatus (detected by anti- $\beta$-COP). A small but significant proportion of pro-caspase-2 protein was present in the nuclear fraction, which contained the nuclear protein PARP. Further fractionation of the cytoplasmic compartment of HeLa cells to obtain a light membrane (LM) and soluble fraction (S) revealed that caspase-2 was barely detectable in the LM fraction but present in the $S$ fraction (Figure $5 \mathrm{~B}$ ). The presence of the large pro-caspase-2 pool in the soluble fraction may be due to weak attachment of pro-caspase-2 to intracellular membranes, which is easily disrupted during fractionation. Alternatively, some pro-caspase-2 might escape from nuclei during fractionation. To explore this further, we studied endogenous caspase-2 localisation by immunofluorescence staining and confocal microscopy in HeLa cells. Caspase- 2 in these analyses was found in the nucleus since it co-localises with DAPI (Figure 5C) and in a cytoplasmic structure that corresponds to the Golgi apparatus since it co-localises with the anti- $\beta$-COP antibody (Figure 5C). Neither the fact that the cytosolic fraction contains most of the Golgi apparatus nor the immunofluoresence staining constitute definitive proof for the association of caspase-2 with this organelle, but they are highly suggestive.

\section{Caspase-2 is not essential for apoptosis}

It has been speculated that in response to many stress signals, caspase-2 may act as either a positive or negative regulator of cell death. Decreasing caspase-2 levels by antisense technology was reported to delay cell death induced by growth factor deprivation in FDC-P1 cells ${ }^{30}$ and PC12 cells. ${ }^{13}$ Furthermore, caspase-2 deficient oocytes were shown to be resistant to apoptosis induced by chemotherapeutic drugs. ${ }^{21}$ However, oocytes may be unique in this regard, since, oocytes appeared to be the only cell types affected by lack 
of caspase-2, ${ }^{21}$ whereas caspase- $2^{-1-}$ lymphocytes were shown to be normally sensitive to chemotherapeutic drugs. We also generated caspase- $2^{-1-}$ mice (Figure 2) and found that in thymocytes, the absence of caspase-2 does not alter the kinetics of cell death or the dose response to a variety of cell death stimuli, including anti-Fas $\mathrm{Ab}(1-1000 \mathrm{ng} / \mathrm{mL})$, the
$\mathbf{A}$

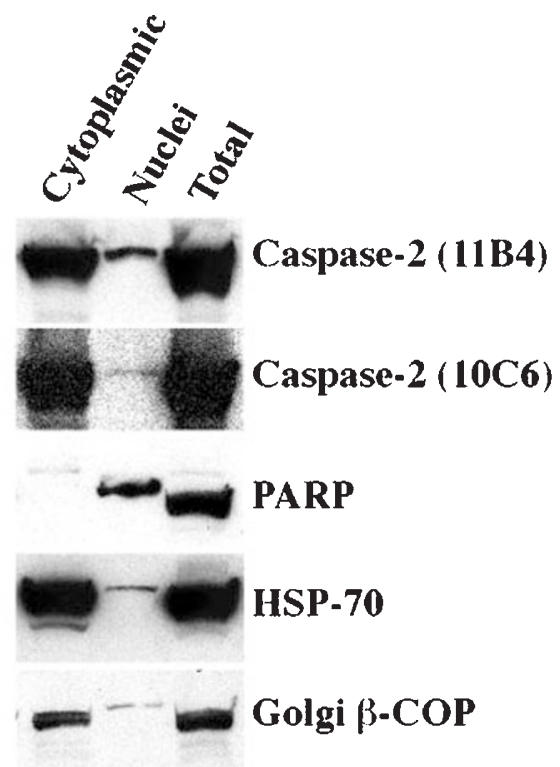

B

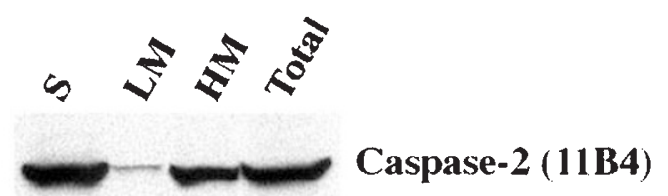

Caspase-2 (10C6)

\section{PARP}

HSP-70

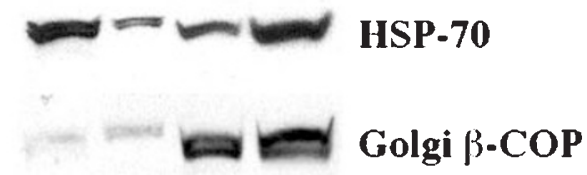

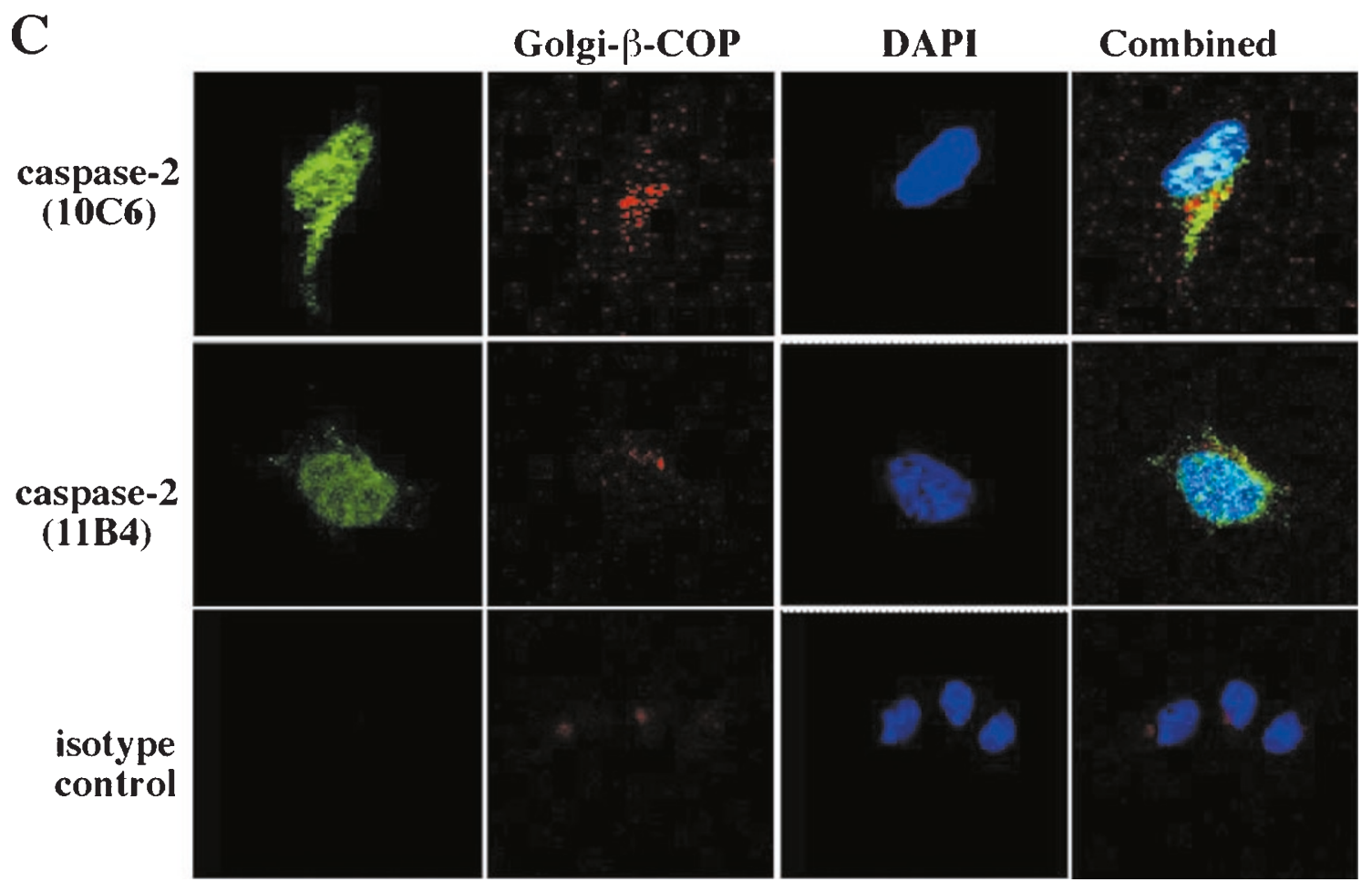

Figure 5 Analysis of caspase-2 localisation by subcellular fractionation and confocal microscopy. (A) Jurkat cell lysates prepared by Dounce homogenisation were separated into nuclear and cytoplasmic fractions. Proteins in fractions were size-fractionated by SDS-PAGE, electroblotted onto membranes and immunoblotting performed with mAbs specific for the proteins indicated. Caspase-2 protein, although found in both the nuclear and cytoplasmic fractions was predominantly expressed in the cytoplasmic fractions in extracts from healthy cells. Data shown are representative of three independent experiments. (B) HeLa cell lysates were prepared by Dounce homogenisation and separated into heavy membrane $(\mathrm{HM})$ and supernatant fractions, the supernatant was further fractionated into light membrane (LM) and soluble fractions (S). Proteins in fractions were size-fractionated by SDS-PAGE, electroblotted onto membranes and immunoblotting performed with anti-caspase-2 mAbs (10C6 or 11B4) or with mAbs specific for the proteins indicated. Caspase-2 is localised in the nucleus and Golgi apparatus in HeLa cells. (C) HeLa cells were fixed, permeabilised, stained with anti-caspase-2 mAbs (10C6 or 11B4) plus FITC-conjugated goat anti-rat IgG antibodies (green), rabbit anti- $\beta$-COP plus biotinylated goat anti-rabbit and streptavidin Texas Red (red) and DAPI (blue) and examined by confocal microscopy 
cytotoxic drug dexamethsone ( $1 \mu \mathrm{M})$ or $\gamma$-irradiation (4-12 Gy) (Figure $6 \mathrm{~A}-\mathrm{C}$ ). This indicates that activation of caspase-2 is not essential for thymocyte apoptosis induced by these stimuli.

Dorsal root ganglion (DRG) neurons from postnatal day 2 wt or caspase- $2^{-/-}$mice were cultured in the presence or absence of NGF and the percentages of live and dead cells at 24 and $48 \mathrm{~h}$ determined by using the MTT assay. DRG neurons from wt and caspase- $2^{-1-}$ mice died at the same rate (Figure 7 ). This contrasts with previous studies, which reported that decreasing caspase-2 levels by anti-sense technology delayed apoptosis induced by trophic factor deprivation in sympathetic neurons. ${ }^{13}$ Our

$\mathbf{A}$

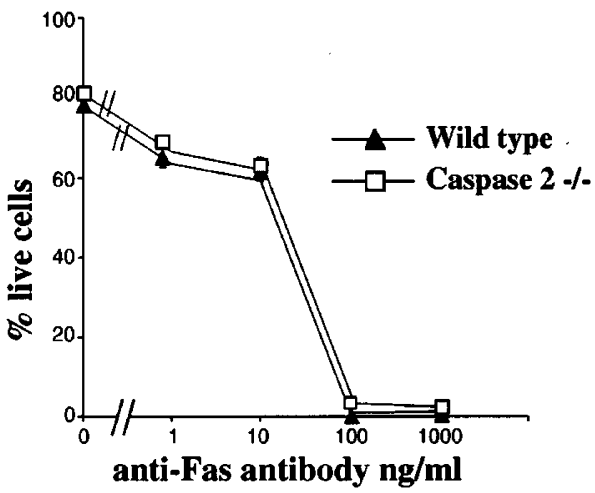

B

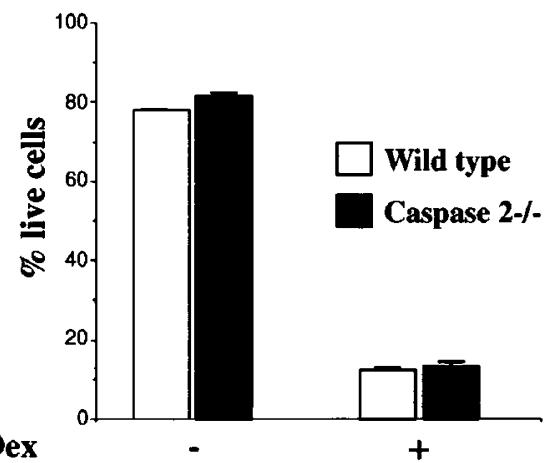

$$
(1 \mu \mathrm{M})
$$

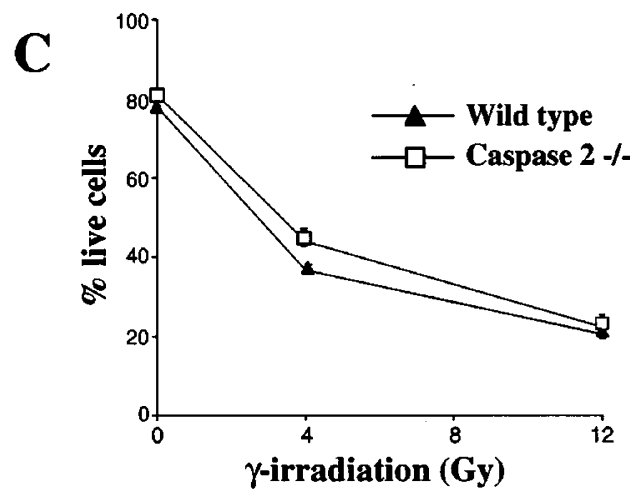

Figure 6 Capase-2 is dispensable for apoptosis in thymocytes. Cell death was induced in wt and caspase- $2^{-1-}$ thymocytes by treatment with $1-$ $1000 \mathrm{ng} / \mathrm{mL}$ anti-Fas $\mathrm{Ab}(\mathbf{A}), 1 \mu \mathrm{M}$ dexamethasone $(\mathbf{B})$ or $\gamma$-irradiation (4-12 Gy) (C). Cell viability was determined by staining with propidium iodide (PI) followed by FACS analysis. Error bars are S.E.M. from three replicate plates observations are, however, in accordance with the observation that caspase-2 deficient sympathetic (SCG) neurons were normally sensitive to NGF withdrawal. $^{21}$ Collectively, these studies indicate that apoptosis in thymocytes and neuronal cells can occur normally in the absence of caspase-2.

\section{Caspase-2 processing in mouse thymocytes requires Apaf-1 and caspase- 9}

Previous studies have indicated that pro-caspase- 2 can be activated by autocatalysis in a proximity-induced manner. ${ }^{18,19}$ However, caspase-2 can also be fully processed by caspase$3^{20}$ and depletion of caspase- 3 from cell extracts blocked caspase-2 processing in vitro. ${ }^{31,32}$ This prompted us to test whether caspase-2 activation can occur in cells lacking Apaf1 or caspase-9, that constitute one of the main caspase-3 activation mechanisms.

We isolated wt, Apaf- $1^{-1-}$ or caspase- $9^{-1-}$ thymocytes from lethally irradiated mice, reconstituted with fetal liver cells derived from wt, Apaf- $1^{-/-}$or Caspase- ${ }^{-/-}$E14 embryos. $\mathrm{CD}^{+} 8^{+}$thymocytes were purified by immunofluorescent staining and flow cytometric cell sorting, and exposed to 5 Gy $\gamma$-irradiation. After 0,4 or $8 \mathrm{~h}$ in culture, cells were harvested, lysed and Western blotting performed with anti-caspase-2 antibodies to follow the appearance of the p32/33 and p19 cleavage products and the disappearance of the p51 pro-form, as a sign of caspase-2 processing. The caspase-2 cleavage products were apparent after $\gamma$-irradiation only in wt thymocytes (Figure 8) but not in those of Apaf- $1^{-1-}$ and caspase- $9^{-1-}$ origin (Figure 8 ). These results demonstrate that in primary cells the cleavage of caspase-2 occurs downstream of the Apaf1/caspase-9 apoptosome complex and are in agreement with the finding that depletion of caspase-9 from cell extracts in vitro abrogates cytochrome $c$-inducible activation of caspase-2. ${ }^{31}$ Thus, Apaf- 1 and caspase- 9 are required for caspase-2 activation.

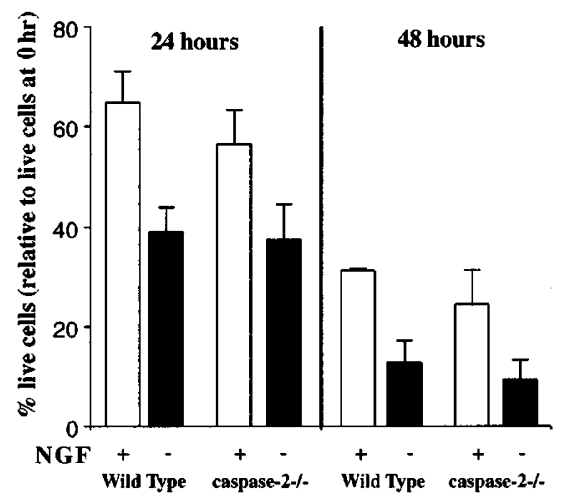

Figure 7 Caspase-2 is not required for trophic factor withdrawal induced apoptosis of DRG neurons. DRG neurons from postnatal day 2 (P2) caspase$2^{-1-}$ mice or control (wt) $\mathrm{C} 57 \mathrm{BL} / 6$ mice were cultured in the presence or absence of NGF. Cell viability was determined by the MTT assay and at each time point a minimum of five individual wells was counted. Data represent the mean of three separate experiments and at least four mice of each genotype were analyzed each time. The error bars represent \pm S.E.M. 


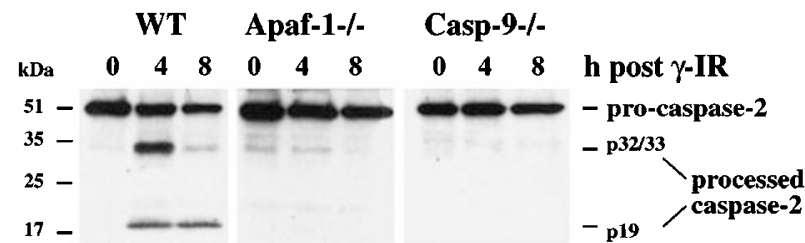

Figure 8 Caspase-2 processing is defective in thymocytes derived from Apaf- 1 and caspase- 9 deficient mice. Cell death was induced in WT Apaf- $1^{-1-}$ or caspase $-9^{-1-}$ thymocytes by $\gamma$-irradiation (5 Gy) and cel lysates were prepared 0,4 and $8 \mathrm{~h}$ after apoptosis induction. Caspase-2 processing was assessed by Western blotting using anti-caspase-2 mAb 11B4 and detected by ECL

\section{Conclusions}

Using monoclonal antibodies that recognize the p19 subunit of caspase-2 we have shown that caspase-2 is expressed in most tissues and cell types. Further, we demonstrate that caspase-2 is located in the nuclear and cytosolic compartments, in particular the Golgi apparatus. Although caspase-2 is activated in response to a broad range of apoptotic stimuli, it is not essential for apoptosis in many cell types, since thymocytes and DRG neuronal cells derived from caspase-2 mutant mice die normally. We also show, that caspase-2 processing during $\gamma$-irradiation induced cell death is dependent on the presence of Apaf-1 and caspase-9. This indicates that cleavage of caspase-2 occurs downstream of the Apaf-1/ caspase- 9 apoptosome and that caspase- 2 processing may be dependent on other caspases, such as caspase-3. We have however seen that in MCF7 cells, that lack the caspase3 gene, ${ }^{33}$ caspase- 2 activation can occur in response to various death stimuli (data not shown). This suggests that caspase- 3 mediated proteolysis may be only one of the ways of caspase-2 activation and in the absence of caspase-3, either an autocatalytic mechanism, or other caspases, such as caspase-7 can still mediate pro-caspase-2 processing. Collectively these observations indicate that in many circumstances caspase-2 may act as an effector caspase. It remains, however, possible that in certain other cell types, such as neuronal cells, caspase- 2 can also function as an initiator caspase, but does so in an overlapping manner with another initiator caspase, such as caspase-9.34 To address the possible overlap between caspase- 2 and caspase- 9 function, it will therefore be interesting to generate mice lacking both of these enzymes.

\section{Materials and Methods}

\section{Experimental animals}

All experiments with animals were performed according to the guidelines laid down by the Royal Melbourne Hospital Research Foundation's Animal Ethics Committee. Wistar rats and C57BL/6 mice were obtained from The Walter and Eliza Hall Institute's breeding facility.

For the generation of caspase- $2^{-1-}$ mice the targeting construct (Figure 2) contained the gene for neomycin resistance under the control of the pgk promoter and a PGK-TK cassette for positive- negative selection. The neo cassette replaced a $1.65 \mathrm{~kb}$ fragment of the caspase-2 gene containing exon 6 (including the catalytic cysteine) and part of exon 7. The construct was linearised and electroporated into w9.5 embryonic stem cells that were selected using gancyclovir and G148 (neomycin). Antibiotic-resistant ES cell clones were isolated, expanded and screened by Southern blot hybridisation using a probe situated at the $3^{\prime}$ end of the deletion construct. ES cells targeted at the caspase-2 locus were confirmed to contain a single integration using a neomycin probe. These cells were used to derive chimaeric mice that were mated with $\mathrm{C} 57 \mathrm{BL} / 6$ female mice and the heterozygous offsprings interbred to yield wild-type caspase $-2^{+/+}$, heterozygous caspase $-2^{+/-}$, and mutant caspase- $2^{-/-}$ mice. Mouse geneotypes were determined by Southern blot analysis of genomic DNA obtained from tail biopsies. Mice were maintained on a mixed 129/sv $\times$ C57BL/6 background. The generation of Apaf-1 mutant and caspase- 9 mice has been described. ${ }^{35,36}$ Apaf- $1^{+/-}$and caspase $-9^{+/-}$animals were backcrossed for $>8$ generations with C57BL/6 mice prior to mating for generation of Apaf-1 ${ }^{-1-}$ and caspase $-9^{-1-}$ embryos.

\section{Production and purification of the hexa-His-tagged Caspase-2 p19 polypeptides}

A region of mouse caspase-2 encoding the $\mathrm{p} 19$ subunit (amino acids 167 to 333) was PCR amplified from pMSN2.4 ${ }^{11}$ and cloned into pQE30 vector (Qiagen) containing an amino terminal $6 \times \mathrm{His}$ tag to generate $\mathrm{pQEp} 19$. Overnight $E$. coli M15(pREP4) cultures harbouring pQEp19 were diluted 50 -fold in fresh medium, grown for $2 \mathrm{~h}$ at $37^{\circ} \mathrm{C}$ and induced with $1 \mathrm{mM}$ IPTG for a further $4 \mathrm{~h}$. Bacterial pellets were lysed in $8.0 \mathrm{M}$ urea, $0.1 \mathrm{M} \mathrm{NaH}_{2} \mathrm{PO}_{4}, 0.01 \mathrm{M}$ Tris $\mathrm{HCl}, \mathrm{pH} 8.0$ and $6 \times$ His-tagged protein purified using a TALON column (Clontech). The recombinant protein was dialysed against PBS, precipitated by cold acetone and redissolved in PBS at $1 \mathrm{mg} / \mathrm{mL}$.

\section{Immunisation, hybridoma fusion and screening for antibodies to caspase-2}

Wistar rats were initially immunised by subcutaneous (s.c.) injection with $100 \mu \mathrm{g}$ purified recombinant $6 \times$ His tagged caspase-2 $\mathrm{p} 19$ subunit mixed with complete Freund's adjuvant (Difco). Two subsequent boosts of the immunogen, resuspended in incomplete Freund's adjuvant (Difco), were injected s.c. 3 and 6 weeks later. A final boost with $\mathrm{p} 19$ protein dissolved in PBS was given intravenously (i.v.) and intraperitoneally (i.p.) 4 weeks after this. Three days later, hybridomas were generated by fusing spleen cells from immunised rats with the SP2/0 myeloma cell line as previously described. ${ }^{22}$ Hybridomas producing monoclonal antibodies to caspase-2 were identified using a screening strategy that we have previously described. $^{22}$ Briefly, 293T cells were transiently transfected with a C-terminally HA-tagged mutant of mouse caspase-2 in which the active site cysteine had been changed to alanine. Transfected cells were fixed in $1 \%$ paraformaldehyde, permeabilised with $0.3 \%$ saponin (Sigma) and stained with hybridoma supernatants. Bound antibodies were revealed with fluorescein-isothyocyanate (FITC)-conjugated goat anti-rat Ig antibodies (Southern Biotechnology) and analysed in a FACScan analyzer (Becton Dickinson). Hybridomas producing antibodies to caspase-2 were cloned twice and adapted for growth in medium containing low serum. For production of large amounts of antibodies, hybridomas were cultured for several weeks in the miniPERM classic $12.5 \mathrm{kDa}$ production and nutrient module (Heraeus). Antibodies were purified on a protein-G Sepharose column (Pharmacia). 


\section{Cell lines, tissue culture, cell death assays and transfection with expression constructs}

The cell lines used for analysis of caspase-2 expression are indicated in Table 1. Details of these cell lines are available from the authors. The cells were cultured in the high glucose version of Dulbecco's modified Eagle's medium (DMEM) supplemented with $10 \%$ foetal calf serum (FCS), $50 \mu \mathrm{M}$ 2-mercaptoethanol (2-ME), $13 \mu \mathrm{M}$ folic acid and $100 \mu \mathrm{M} \mathrm{L}$-asparagine or were grown in DME or RPMI medium with $10 \%$ FCS alone. Cultures of parental FDC-P1 and BAF-3 cells and their derivatives were supplemented with IL-3 (1000 U/mL). Granulocyte differentiation of $34.6 \mathrm{Myl}$ cells was induced by the addition of $1.5 \%$ dimethyl sulfoxide. ${ }^{37}$ Liposome (Lipofectamine, Gibco BRL) mediated transfection of 293T cells was performed as previously described. $^{38}$

Apaf- $1^{-1-}$ and caspase $-9^{-1-}$ thymocytes were isolated from C57BL/6-Ly5.1 mice, which had been lethally irradiated $(2 \times 5.5$ Gy) and reconstituted with foetal liver cells from wild-type (wt), Apaf-1 ${ }^{-1-}$ or Caspase- $9^{-1-}$ E14 fetuses (all $>8$ generations C57BL/6-Ly5.2). These fetuses were generated by intercrosses of either Apaf- $1^{+/-35}$ or Caspase $-9^{+/-}$mice. ${ }^{36}$ Donor $\left(\right.$ Ly $\left.5.2^{+}\right)$-derived CD $4^{+} 8^{+}$thymocytes were purified by immunofluorescent staining with monoclonal antibodies to Ly5.2, CD4 and CD8, followed by cell sorting in a MoFlo (cytomation). ${ }^{39}$ These thymocytes were left untreated or were exposed to 5 Gy $\gamma$-irradiation. After 4 or $8 \mathrm{~h}$ in culture, cells were harvested, lysed and Western blotting performed with anti-caspase-2 antibodies.

In BAF-3 and FDC-P1 cells, apoptosis was induced by withdrawal of IL-3, their essential growth factor. Cell viability was determined by counting cells stained with the vital dye Trypan Blue.

Thymocytes from wild-type (wt) or caspase- $2^{-1-}$ mice were cultured in DMEM supplemented with $10 \%$ foetal calf serum (FCS), $50 \mu \mathrm{M}$ 2-mercaptoethanol (2-ME), $13 \mu \mathrm{M}$ folic acid and $100 \mu \mathrm{M}$ Lasparagine at $10^{6} / \mathrm{ml}$. Cell death was induced by treatment with either $1-1000 \mathrm{ng} / \mathrm{ml}$ anti-Fas Ab (Jo2, Pharmingen), $1 \mu \mathrm{M}$ dexamethasone (Sigma) or $\gamma$-irradiation (4-12 Gy). Cell viability was determined after $24 \mathrm{~h}$ by propidium iodide (PI) staining and analysis in a FACScan.

Dorsal root ganglion (DRG) neuronal cells from wt and caspase$2^{-I-}$ mice were prepared as described ${ }^{40}$ from post-natal day 2 mice. Briefly, DRGs were dissected free of surrounding tissue and incubated in HEPES-buffered Eagles medium (HEM), 0.025\% trypsin, $0.001 \%$ DNAse for $30 \mathrm{~min}$. FCS was added (10\%) and cells centrifuged at $300 \times g$ for $5 \mathrm{~min}$, resuspended in HEM, 10\% FCS, $0.01 \%$ DNAse and triturated through 18 to 24 gauge needles to obtain a single cell suspension. Cells were washed in HEM, 10\% FCS, 0.01\% DNAse and resupended in Monomed, 10\% FCS. To assess DRG neuron survival, single cell suspensions were resupsended at a density of $10^{4}$ cells $/ \mathrm{mL}$ with or without added nerve growth factor $(2.5 S \mathrm{NGF}, 10 \mathrm{ng} / \mathrm{mL}$, Sigma). Cells were plated on fibronectin (Sigma) coated Terasaki plates at approximately 100 cells/well. At each time point, at least five wells were stained with MTT $(0.5 \mathrm{mg} / \mathrm{mL}$ 3-(4,5-dimethythiazol-2,5diphenyltetrazolium bromide, Sigma) for $1-2 \mathrm{~h}$ at $37^{\circ} \mathrm{C}$ and viable (blue stained cells) counted. This number was expressed as a percentage of the mean number of surviving cells at $0 \mathrm{~h}$.

\section{Western blotting}

Primary cells, cell lines or transfected 293T cells were harvested, washed twice in cold PBS and lysed in lysis buffer $(20 \mathrm{mM} \mathrm{Tris} / \mathrm{HCl}$, $\mathrm{pH} 8.0,125 \mathrm{mM} \mathrm{NaCl}, 1 \mathrm{mM}$ EGTA, 1\% Triton X-100, 10\% glycerol, $0.5 \mu \mathrm{g} / \mathrm{mL}$ Pefabloc, $1 \mu \mathrm{g} / \mathrm{mL}$ of each of leupeptin, aprotinin, soybean trypsin inhibitor and pepstatin, $5 \mathrm{mM} \mathrm{NaF}$ and $2 \mathrm{mM} \mathrm{Na}_{3} \mathrm{VO}_{4}$; all reagents from Sigma or Roche Diagnostics). For preparation of tissue lysates, organs were excised, washed in PBS, immediately frozen in isopentane on dry ice, and were later homogenised at $4^{\circ} \mathrm{C}$ in lysis buffer as described before. ${ }^{41}$

Proteins in cell lysates were size-fractionated by SDS-PAGE and electroblotted onto nitrocellulose membranes (Amersham LifeScience). Prior to immunoblotting, non-specific binding of antibodies to membranes was blocked by incubation overnight in 5\% skimmed milk, $1 \%$ casein, $0.05 \%$ Tween-20. Membranes were probed with $10 \mathrm{C} 6$ or $11 \mathrm{~B} 4$ anti-caspase-2 $\mathrm{mAbs}(1 \mu \mathrm{g} / \mathrm{mL})$ followed by goat anti-rat IgG antibodies conjugated to HRP (Southern Biotechnology) and detection by enhanced chemiluminescence (ECL; Amersham Pharmacia). To control for the concentration and integrity of proteins in the tissue lysates, blots were probed with mouse anti-HSP70 mAb N6 (a gift from $\mathrm{Dr} \mathrm{R}$ Anderson, Peter MacCallum Cancer Institute, Melbourne, Australia), followed by HRP-conjugated sheep anti-mouse Ig antibodies (Silenus) and detection by ECL.

\section{Subcellular fractionation}

Jurkat or HeLa cells were resuspended in hypotonic buffer (either $0.01 \mathrm{M} \mathrm{NaCl}, 1.5 \mathrm{mM} \mathrm{MgCl} 2,0.01 \mathrm{M}$ Tris- $\mathrm{HCl}, \mathrm{pH} 7.4$ or $10 \mathrm{mM}$ HEPES pH 7.4, $38 \mathrm{mM} \mathrm{NaCl}$ ) and allowed to swell on ice for $10 \mathrm{~min}$ at $4{ }^{\circ} \mathrm{C}$. Cells were lysed using a Dounce homogeniser (12-36 strokes with a type ' $B$ ' pestle; Konte Glassware Corporation). ${ }^{42}$ After 3 min centrifugation at $1000 \times g$ at $4{ }^{\circ} \mathrm{C}$, followed by two washes in hypotonic buffer, the pelleted nuclei or heavy membranes (HM) were resuspended in the lysis buffer used for Western blotting (see above). The resulting supernatant was fractionated further by centrifugation at $130000 \times \mathrm{g}$ for $1 \mathrm{~h}$ (or 50000 r.p.m. for $30 \mathrm{~min}$ in a TLA 100.3 Beckman benchtop rotor) to generate the soluble (S) and light membrane (LM) fractions. The LM pellet was resuspended in RIPA buffer (150 mM NaCl, 1\% Triton X-100, 0.5\% deoxycholic acid, $50 \mathrm{mM}$ Tris- $\mathrm{HCl}$ pH 8.0 plus protease inhibitors). Lysates from equivalent numbers of cells were analyzed by immunoblotting with the rat anticaspase-2 mAbs $10 \mathrm{C} 6$ or $11 \mathrm{~B} 4$, the mouse mAb anti-PARP (Calbiochem-Novabiochem Corp), rabbit anti-Golgi $\beta$-COP (Affinity Bioreagents Inc) or mouse anti-HSP-70 mAb. Bound antibodies were revealed with appropriate HRP-conjugated anti-mouse, anti-rat or antirabbit Ig antibodies and ECL detection.

\section{Immunofluorescence staining and confocal microscopy}

For immunofluorescence staining with anti-caspase-2 mAbs, HeLa cells were grown in chamber slides (Becton Dickinson). Cells were attached using Cell Tak (Becton Dickinson), fixed and permeabilized with $\mathrm{PBS} / 4 \%$ paraformaldehyde, containing $0.18 \%$ Triton $\mathrm{X}-100$ for 10 min at RT. The fixed cells were stained overnight at $4{ }^{\circ} \mathrm{C}$ with the rat anti-caspase-2 10C6 or 11B4 mAbs in PBS containing 10\% FCS, washed with PBS and then incubated with FITC-conjugated goat antirat Ig antibodies (Southern Biotechnology). The slides were then reblocked with normal goat serum and stained rabbit anti-beta-Coatomer protein ( $\beta$-COP) antibody (Affinty BioReagents, Inc) in PBS containing $10 \%$ FCS, followed by biotinylated goat anti-rabbit IgG antibodies (Vector) in PBS containing 10\% FCS. Staining was detected by Texas Red conjugated strepavidin (Vector) containing DAPI $(2 \mu \mathrm{g} / \mathrm{mL}$, Molecular Probes). Slides were mounted in fluorescent mounting medium (Dako) containing $100 \mu \mathrm{g} / \mathrm{mL}$ DIABCO (Sigma). Controls included staining with an isotype matched rat $\lg \mathrm{G} 2 \mathrm{a}$ antibody (Pharmingen) or with the primary or secondary antibodies alone. Samples were analysed with a Leica confocal scanning microscope using SCANware software (Leica Lasertechnik). 


\section{Acknowledgements}

We are grateful to Prof. Peter Gruss (Max Plank Institute, Goettingen, Germany) for supplying the Apaf-1 ${ }^{+/-}$mice. We thank S Novakovic, G Hausmann, F Battye, D Kaminaris, J Parker, V Lapatis, C Tarlinton, A Milligan and $\mathrm{J}$ Merryfull for help with various aspects of this study. This work was supported by grants and fellowships from, the Leukemia and Lymphoma Society of America (New York), the Anti-Cancer Foundation of South Australia, the Anti-Cancer Council of Victoria, the Nationa Health and Medical Research Council, the Sylvia and Charles Viertel Charitable Foundation, the Dr. Josef Steiner Cancer Research Foundation (Bern, Switzerland) and The Murdoch Children's Research Institute.

\section{References}

1. Nicholson DW (1999) Caspase structure, proteolytic substrates, and function during apoptotic cell death. Cell Death Differ. 6: 1028-1042

2. Kumar S and Colussi PA (1999) Prodomains - adaptors - oligomerization: the pursuit of caspase activation in apoptosis. Trends Biochem. Sci. 24: 1-4

3. Strasser A, O'Connor L and Dixit VM (2000) Apoptosis signaling. Annu. Rev. Biochem. 69: 217-245

4. Boldin MP, Varfolomeev EE, Pancer Z, Mett IL, Camonis JH and Wallach D (1995) A novel protein that interacts with the death domain of Fas/APO1 contains a sequence motif related to the death domain. J. Biol. Chem. 270: 7795-7798

5. Chinnaiyan AM, O'Rourke K, Tewari M and Dixit VM (1995) FADD, a novel death domain-containing protein, interacts with the death domain of Fas and initiates apoptosis. Cell 81: $505-512$

6. Boldin MP, Goncharov TM, Goltsev YV and Wallach D (1996) Involvement of $\mathrm{MACH}$, a novel MORT1/FADD-interacting protease, in Fas/APO-1- and TNF receptor-induced cell death. Cell 85: 803-815

7. Muzio M, Chinnaiyan AM, Kischkel FC, O'Rourke K, Shevchenko A, Ni J, Scaffidi C, Bretz JD, Zhang M, Gentz R, Mann M, Krammer PH, Peter ME and Dixit VM (1996) FLICE, a novel FADD homologous ICE/CED-3-like protease, is recruited to the CD95 (Fas/Apo-1) death-inducing signaling complex. Cell 85: 817-827

8. Salvesen GS and Dixit VM (1999) Caspase activation: the induced-proximity model. Proc. Natl. Acad. Sci. USA 96: 10964-10967

9. Li P, Nijhawan D, Budihardjo I, Srinivasula SM, Ahmad M, Alnemri ES and Wang X (1997) Cytochrome $c$ and dATP-dependent formation of Apaf-1/Caspase-9 complex initiates an apoptotic protease cascade. Cell 91: 479-489

10. Zou H, Henzel WJ, Liu X, Lutschg A and Wang X (1997) Apaf-1, a human protein homologous to $C$. elegans CED-4, participates in cytochrome c-dependent activation of Caspase-3. Cell 90: 405-413

11. Kumar S, Kinoshita M, Noda M, Copeland NG and Jenkins NA (1994) Induction of apoptosis by the mouse Nedd2 gene, which encodes a protein similar to the product of the Caenorhabditis eleganscell death gene ced-3and the mammalian IL-1 $\beta$-converting enzyme. Genes Dev. 8: 1613-1626

12. Kumar S, Kinoshita M, Dorstyn L and Noda M (1997) Origin, expression and possible functions of the two alternatively spliced forms of the mouse Nedd2 mRNA. Cell Death Differ. 4: 378-387

13. Troy CM, Stefanis L, Greene LA and Shelanski ML (1997) Nedd2 is required for apoptosis after trophic factor withdrawal, but not superoxide dismutase (SOD1) downregulation, in sympathetic neurons and PC12 cells. J. Neurosci. 17: 1911 1918

14. Nicholson DW and Thornberry NA (1997) Caspases: killer proteases. Trends Biochem. Sci. 22: 299-306

15. Duan H and Dixit VM (1997) RAIDD is a new 'death' adaptor molecule. Nature 385: $86-89$

16. Shearwin-Whyatt LM, Harvey NL and Kumar S (2000) Subcellular localization and CARD-dependent oligomerization of the death adaptor RAIDD. Cell Death Differ. 7: 155-165

17. Harvey NL, Butt AJ and Kumar S (1997) Functional activation of Nedd2/ICH-1 (caspase-2) is an early process in apoptosis. J. Biol. Chem. 272: 13134-13139

18. Butt AJ, Harvey NL, Parasivam G and Kumar S (1998) Dimerization and autoprocessing of the Nedd2 (caspase-2) precursor requires both the prodomain and the carboxyl-terminal regions. J. Biol. Chem. 273: 6763-6768
19. Colussi PA, Harvey NL and Kumar S (1998) Prodomain-dependent nuclear localization of the caspase-2 (Nedd2) precursor. A novel function for a caspase prodomain. J. Biol. Chem. 273: 24535-24542

20. Harvey NL, Trapani JA, Fernandes-Alnemri T, Litwack G, Alnemri ES and Kumar $S$ (1996) Processing of the Nedd2 precursor by ICE-like proteases and granzyme B. Genes Cells 1: 673-685

21. Bergeron L, Perez GI, Macdonald G, Shi L, Sun Y, Jurisicova A, Varmuza S, Latham KE, Flaws JA, Salter JC, Hara H, Moskowitz MA, Li E, Greenberg A, Tilly $\mathrm{JL}$ and Yuan J (1998) Defects in regulation of apoptosis in caspase-2-deficient mice. Genes Dev. 12: $1304-1314$

22. O'Reilly LA, Cullen L, Moriishi K, O'Connor L, Huang DCS and Strasser A (1998) Rapid hybridoma screening method for the identification of monoclonal antibodies to low abundance cytoplasmic proteins. BioTechniques 25: 824-830

23. Garcia-Calvo M, Peterson EP, Leiting B, Ruel R, Nicholson DW and Thornberry NA (1998) Inhibition of human caspases by peptide-based and macromolecular inhibitors. J. Biol. Chem. 273: 32608-32613

24. Kumar S, Kinoshita M and Noda M (1997) Characterization of a mammalian cell death gene Nedd2. Leukemia 11 (Suppl 3): 385-386

25. Droin N, Rébé C, Bichat F, Hammann A, Bertrand R and Solary E (2001) Modulation of apoptosis by procaspase-2 short isoform: selective inhibition of chromatin condensation, apoptotic body formation and phosphatidylserine externalization. Oncogene 20: 260-269

26. Zhivotovsky B, Samali A, Gahm A and Orrenius S (1999) Caspases: their intracellular localization and translocation during apoptosis. Cell Death Differ. 6 : $644-651$

27. Susin SA, Lorenzo HK, Zamzami N, Marzol, Brenner C, Larochette N, Prevost MC, Alzari PM and Kroemer G (1999) Mitochondrial release of caspase-2 and -9 during the apoptotic process. J. Exp. Med. 189: 381-394

28. Mancini M, Machamer CE, Roy S, Nicholson DW, Thornberry NA, CasciolaRosen LA and Rosen A (2000) Caspase-2 is localized at the Golgi complex and cleaves golgin-160 during apoptosis. J. Cell Biol. 149: 603-612

29. Hsu YT and Youle RJ (1997) Nonionic detergents induce dimerization among members of the Bcl-2 family. J. Biol. Chem. 272: 13829-13834

30. Kumar S (1995) Inhibition of apoptosis by the expression of antisense Nedd2. FEBS Lett. 368: $69-72$

31. Slee EA, Harte MT, Kluck RM, Wolf BB, Casiano CA, Newmeyer DD, Wang HG, Reed JC, Nicholson DW, Alnemri ES, Green DR and Martin SJ (1999) Ordering the cytochrome $c$-initiated caspase cascade: hierarchical activation of caspases-2, -3, -6, -7, -8, and -10 in a caspase-9- dependent manner. J. Cell Biol. 144: 281-292

32. Paroni G, Henderson C, Schneider C and Brancolini C (2001) Caspase-2induced apoptosis is dependent on caspase-9, but its processing during UV- or tumor necrosis factor-dependent cell death requires caspase-3. J. Biol. Chem. 276: $21907-21915$

33. Janicke RU, Sprengart ML, Wati MR and Porter AG (1998)Caspase-3 is required for DNA fragmentation and morphological changes associated with apoptosis. J. Biol. Chem. 273: 9357-9360

34. Troy CM, Rabacchi SA, Hohl JB, Angelastro JM, Greene LA and Shelanski ML (2001) Death in the balance: alternative participation of the caspase-2 and -9 pathways in neuronal death induced by Nerve Growth Factor deprivation. J. Neurosci. 21: $5007-5016$

35. Cecconi F, Alvarez-Bolado G, Meyer BI, Roth KA and Gruss P (1998) Apaf-1 (CED-4 homologue) regulates programmed cell death in mammalian development. Cell 94: 727-737

36. Kuida K, Haydar TF, Kuan C-Y, Gu Y, Taya C, Karasuyama H, Su MS-S, Rakic P and Flavell RA (1998) Reduced apoptosis and cytochrome c-mediated caspase activation in mice lacking caspase 9. Cell 94: 325-337

37. Elefanty AG and Cory S (1992) bcr-ab/-Induced cell lines can switch from mast cell to erythroid or myeloid differentiation in vitro. Blood 79: 1271-1281

38. Huang DCS, O'Reilly LA, Strasser A and Cory S (1997) The anti-apoptosis function of $\mathrm{Bcl}-2$ can be genetically separated from its inhibitory effect on cell cycle entry. EMBO J. 16: 4628-4638

39. O'Reilly LA, Huang DCS and Strasser A (1996) The cell death inhibitor Bcl-2 and its homologues influence control of cell cycle entry. EMBO J. 15: 6979-6990

40. Murphy M, Reid K, Hilton DJ and Bartlett PF (1991) Generation of sensory neurons is stimulated by leukemia inhibitory factor. Proc. Natl. Acad. Sci. USA 88: $3498-3501$ 
41. Print CG, Loveland KL, Gibson L, Meehan T, Stylianou A, Wreford N, de Kretser D, Metcalf D, Köntgen F, Adams JM and Cory S (1998) Apoptosis regulator Bcl-w is essential for spermatogenesis but appears otherwise redundant. Proc. Natl. Acad. Sci. USA 95: 12424-12431
42. Hausmann G, O'Reilly LA, van Driel R, Beaumont JG, Strasser A, Adams JM and Huang DCS (2000) Pro-apoptotic apoptosis protease-activating Factor 1 (Apaf1) has a cytoplasmic localization distinct from Bcl-2 or Bcl- $x_{L}$. J. Cell Biol. 149: $623-634$ 